\title{
Approaches in Redesigning the Organization of Local Apparatus \\ How and Which One Is More Effective?
}

\author{
Nunung Runiawati \\ Departement of Public Administration \\ Universitas Padjadjaran \\ Bandung, Indonesia \\ n.runiawati@unpad.ac.id
}

\author{
Heru Nurasa \\ Departement of Public Administration \\ Universitas Padjadjaran \\ Bandung, Indonesia \\ h.nurasa@yahoo.com
}

\begin{abstract}
An organizational structure is a means of achieving the goals of the organization. Demands to improve the performance of local government organization are often obstructed by the existing structure. Therefore it needs the organizational restructuring. This research aims to identify stages of organizational design and to find out the most effective organizational structure. It applies organizational design theories proposed by some experts. It employs qualitative methods with case study approaches. The result shows that there are five stages in designing an organization, comprising: determining the direction of the change in the organizational design, determining the workflow, departmentalization, and determining tasks of each working unit. Based on the research conducted on both organizations of local apparatus, the effective departmentalization uses the hybrid method. At the level of supporting staff, the most effective method is based on the function, while at middle line it is based on products or customers' area.
\end{abstract}

Keywords - Redesigning; Organization; Work Flow; Task Grouping; Hybrid

\section{INTRODUCTION}

Organizational structure is the means utilized by the management to achieve the goal of the organization [1]. The choice of the organizational design is crucial because some components in the organizational structure should be designed in such a way that it will ensure the efficiency and effectiveness of the work.

Subsequently, the change of the environment, such as global economy, social, political, information technology conditions may cause the shift in the organization's paradigm. The change in the organization's paradigm may become one of the reasons why restructuration of the organization is necessary. Even, a critical success factor for organizations today is the ability to adapt their structures, systems and processes to achieve the goal of the organization [2] because

The Project Supported by (Regional Revenues and Expenditures Budget of Bandung City)

Corresponding Author: (Nunung Runiawati \& Heru Nurasa) in essence an organization is formed to make a change [3].

To realize good governance, the government has enacted the agenda of bureaucracy reform. Bureaucracy reform has some goals; one of them is to improve the professionalism and performance of the organization. In this case, the Local Government as one of the spearheads of public services faces some problems with current bureaucracy, such as the organization which has not functioned properly, the low quality and productivity of state civil apparatus, public services which have not met the public's needs (unprofessional), inefficiency, ineffectiveness, etc. Therefore, many organizations of local apparatus have made changes in their structure, because the existing structure is considered to be unable to respond the demand for bureaucracy reform.

This restructuring aims to the need to improve business performance through cost reductions or productivity gains (Balogun and Hope Hailey, 2003)[4] adopt new, more flexible and modular organizational forms to respond to an increasingly dynamic business environment [4] [5], or the need for more globally integrated ways of working [4] [6]. The choice of the design when restructuring the organization can be driven by a number of strategic consideration, such as knowledge creation process which constitutes a background for Nonaka and Takeuchi [7] in developing the hypertext organization theory, statement of strategic intent [1] [8], five basic elemets of the organization [9].

This research lifts up case studies on the stages of the organizational design conducted in two local apparatus organizations in Bandung City. The first case study was conducted in 2013 in Local Company of Sanitation (PD Kebersihan) of Bandung City, one of local government-owned enterprises (BUMD) owned by the City Government of Bandung, which has two main objectives, public services and profit taking. The second case study was conducted by the Office which manages Local Taxes in 2012 and 2015.

\section{A. Problem Statement and Research Question}

The backgrounds of the change of the post-reform organizational design in local governments are dynamic 
changes of the regulation on post-reform organization of local governments and the demand for the improvement of the organization's professionalism and performance.

When this research was conducted, the change of the organization of local apparatus followed the Government Regulation Number 41 Year 2007 on the Organization of Local Apparatus, Article 29 paragraph (1) which regulates that:

"Local Office consists of 1 (one) secretariat and at most 4 (four) sectors, a secretariat consists of 3 (three) subdivision, and each sector consists of at most 3(three) sections".

Based on this provision, there is a separation between the line function and the staff function. The line function is conducted by the Sector, while the staff function is conducted by the Secretariat. However, during the implementation, the separation is not clear hence the overlap of authority occurs.

This research would focus on how the stages in designing the organization are conducted so that the job distribution between the line function and the staff function becomes clear and also what is the form of the most effective departmentalization conducted in the organization of local apparatus, especially Local Offices in achieving the goal of the organization.

The research questions in this article are:

1. How are the stages in designing the organization of local apparatus conducted?

2. What is the form of the most effective departmentalization implemented in the organization of local apparatus?

\section{B. Research Objectives}

This research provides the comprehension of the stages in conducting the organizational design, particularly the organization of local apparatus and also provides suggestions to conduct the most effective departmentalization applied in the organization of local apparatus.

\section{METHODOLOGY}

This research uses the qualitative method with case study approach in designing the organization of local apparatus conducted in two organizations of local apparatus in Bandung City, namely Local Companion of Sanitation (PD Kebersihan) of Bandung City in 2013 and the Office that manages Local Taxes in 2012 and 2015.

The data collection technique was conducted through indepth interviews with officials at the levels of top, middle and lower management in both organizations of local apparatus, focus group discussions among stakeholders, observation and literature review.

\section{III.RESULTS AND DISCUSSION}

\section{A. Stages of Organizational Redesign}

Stages of the organizational redesign in this research are focused by considering the approach in organizational design proposed by experts which is subsequently adjusted to obtain the most effective organizational design. There are four stages that must be passed through in redesigning organizational structure, namely:

1. Determining the Direction of the Change in Organizational Design

The goals of the organization are the important factor in determining the direction of the change in organizational structure, hence Terry (1975), Mintzberg (1983), Nonaka (1983), Mc Gee and Moloy (2003) made it the early stage in designing an organization. The experts use different terms for it, such as objectives (Terry, 1975), statement or strategic intents (Mintzberg, 1983), hypertext organization (Nonaka, 1983) or superstructure (Mc Gee and Moloy 2003).

The research result indicates that stressing is necessary in this stage due to two reasons, the first that the authority of local apparatus is regulated by the central government hence if the regulation of the central government changes, then the strategy of local apparatus also changes. The second, the change of external environment, such as communication technologies, the public's demand, and social, economic, and political condition, which requires the organization of local apparatus to adjust to the existing development. Therefore, there are 4 (four) stages in determining the direction of the change in the organizational structure.

The first stage is to identify the goals of the organization. An organizational structure is the tools for the managers of the organization to realize the vision and mission of the organization. The identification of the goals is conducted through two methods, Focused Group Discussion (FGD) and analysis of related documents of the company.

After the goals have been identified, the next stage is to analyze the compatibility of the goals of the organization with current situation which is conducted through the analysis of Strengths, Weaknesses, Opportunities, Threats (SWOT). It is necessary considering that sometimes the goals of the organization in Local Governments are unable to respond to the desired change. It may be caused by the obligation to adapt to the change in the central government's regulation or other demands unpredicted before. The data needed for analyzing SWOT are obtained through:

(1) FGD and in-depth interviews to identify strengths and weaknesses of the work implementation by using the current structure;

(2) Analysis of the Documents of the Company;

(3) Analysis of regulation (the 1945 Constitution, the Laws, the Government Regulation, the Minister Regulation, and other related regulations, which is conducted to ensure that the Local Government's activities are in accordance with the central government's regulation;

(4) Data of suggestion and complaint from the public as the service users.

The third stage is to determine the direction of the arrangement of the change in the organizational structure. It functions as the backbone of the change in the organizational structure. 


\section{Case Study:}

Determination of the Direction of the Change in the Organizational Structure of the Local Companion of Sanitation (PD Kebersihan) of Bandung City: "new organizational structure must depict a business entity as a Local Government-Owned Enterprises which does not only have a function to perform public services but is also able to perform self-financing, even further is able to make a profit (profitability)".

The Office of Tax Services of Bandung City: "improvement of departmentalization in each working unit in order to be able to bring the service closer to the public (among other things, through the affirmation of the role of UPP and information system) and also improving the effectiveness of tax revenues".

The fourth stage is to establish mutual commitment in order to determine the direction of the arrangement of the change in the organization. At this stage the leadership ability of the head of Organization of Local Apparatus is necessary for managing the change in the organization. It aims to avoid conflicts of interest among members of the organization during the process of preparing the organizational structure.

\section{Determining the Workflow}

Workflow is the backbone in organizing. Besides that, it affects the performance of the organization, particularly the aspects of cost, quality, time or flexibility [8]. Therefore, this stage becomes important and it is the most complex among other stages. The sub-stages that must be passed through are as follows:

a) Identification of the existing workflow and strengths and weaknesses related to the existing workflow; in the organizations of local apparatus which have had the document of standard operating procedures (SOP) for identifying the workflow it is relatively easy to perform, but if the organizations of local apparatus have not had SOP, the process needs to be identified through in-depth interviews, observation, and related documents/regulation.

\section{Case Study:}

1. The Local Companion of Sanitation (PD Kebersihan) of Bandung City does not have SOP hence the identification of the workflow is conducted through FGD, in-depth interviews, observation, and studies of documents. Based on the research result the outline of the work flow is obtained as follows: sorting $\rightarrow$ sweeping of main roads $\rightarrow$ transporting garbage from temporary collection sites to final collection sites $\rightarrow$ garbage treatment $\rightarrow$ final garbage processing. Based on the research result, it is found that the garbage treatment process, especially inorganic waste has not been optimum, although it is an opportunity to earn profits if the Local Companion of Sanitation (PD Kebersihan) of Bandung City is able to process the waste into value-added products.
2. In the Office of Tax Services some divisions have had SOP. To identify the workflow of other divisions, data collection was conducted through the identification of the workflow which was done through FGD, in-depth interviews, observation, and studies of documents. Hence in an outline the workflow of the management of local taxes consists of local taxation planning $\rightarrow$ performance local tax collection and administration $\rightarrow$ control of local taxes. Based on the research result, it is known that there is an overlap of work among the divisions and the performance of the work is not in accordance with their authority.

b) Assessment of compatibility; at this stage the assessment needs to be conducted between the existing workflow and the direction of the change in the organization.

Case Study:

1. Local Companion of Sanitation (PD Kebersihan) of Bandung City

The assessment result shows that the effort to handle cannot be separated from the effort to reduce, because the handling shows activities while the waste reduction shows the goal of the activity of waste handling itself. Both are built in at the activity of waste handling in Bandung City. Therefore the derivative activities of waste handling are designed in such a way to reduce waste. On the other side, if we refer to the Local Bylaw 14/2011, the Local Companion of Sanitation (PD Kebersihan) of Bandung City is provided with an opportunity to perform other efforts in the field of waste management. Therefore, some work processes need to be strengthened, such as:

i. Waste sorting process which involves the public;

ii. Schedules of transportation of organic waste and inorganic one which are differentiated to facilitate the waste sorting;

iii. Processing of organic waste and inorganic waste;

iv. Waste disposal to final collection site which is attempted to dispose only the residual product of the waste processing which cannot be recycled;

v. Strengthening the function of dunning;

vi. Strengthening the function of marketing.

2. Office of Tax Services of Bandung City

In order to support the current vision and mission of Mayor of Bandung, "Bandung Juara (Bandung the Champion)" by advancing the spirit of innovation, decentralization, and collaboration to make the service closer to the public, collection service unit (UPP) and information system play a central role. The assessment result shows that the strengthening must be emphasized at:

3. Strengthening the role of collection service unit (UPP) in the matters of tax service, consultation and complaint service, and other additional tasks. 
4. Strengthening the role of information system hence some workflows are simplified

5. Strengthening the role of the Planning Sector so that multi-interpretation or underload capacity does not occur

6. Regrouping of Sections of the Local Taxation Sector so that the work performance is more effective and load allocation is proportionally distributed.

7. Strengthening the Control Sector in order to obtain New Taxable Subjects and increasing the number of Taxable Subjects that keep on paying taxes.

\section{Make a Modification If Necessary}

Modification in a business process is a must to ensure that the work process becomes more effective and efficient.

\section{Task Grouping}

The basic principle of departmentalization is to perform work separation between the line function (core business) and the staff function (auxiliary). Mintzberg explained this in detail in a concept known as 5 basic configurations of an organization. In the organizational structure of local apparatus, the five configurations cannot be wholly adopted because the structure design of the organization of local apparatus follows the mandate of regulation, in which its parts comprise strategic apex, middle line, operating core and supporting staff, while the position of techno structure is not described in the structure of the organization of local apparatus (see Fig. 1).

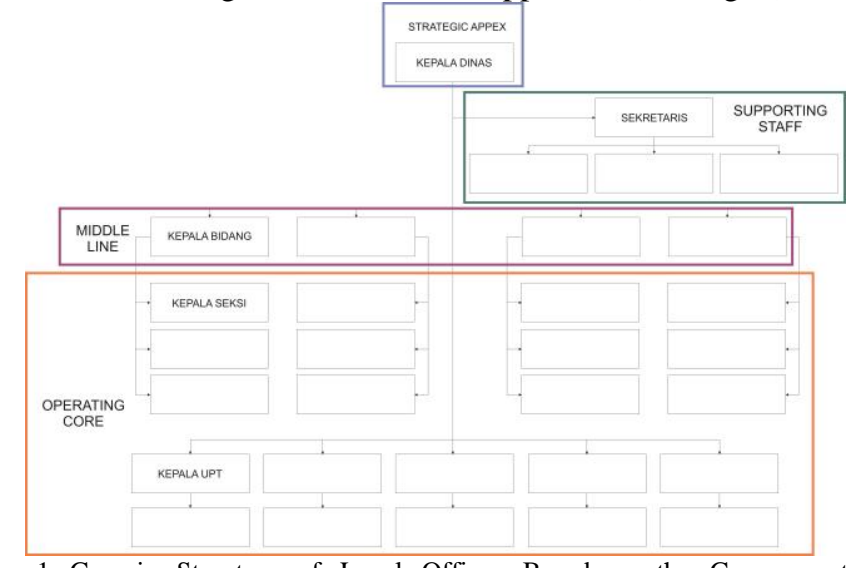

Fig. 1 Generic Structure of Local Offices Based on the Government Regulation 27/2007

The line function is represented by the middle line, while the staff function is represented by the supporting staff. Departmentalization in each of working units, both those of the line function and the staff function, becomes a crucial factor in the performance of organizational design. At this stage it is necessary to carefully analyze what form of grouping is the most effective in achieving the goals of the organization and the most efficient in allocating the existing resources based on similarity and proportional distribution of work load among working units. The bases of departmentalization as proposed by Mintzberg (1983) are the grouping by knowledge and skill, grouping by work process and function, grouping by time, grouping by output, grouping by client or grouping by place.

\section{Case Study}

Grouping at the Local Companion of Sanitation (PD Kebersihan) of Bandung City

1. Before Redesigning

In the existing organization structure, the middle line consists of two Directors: (1) Technical and Operational Director who performs the service of waste management in Bandung City or performs the line function (core business); (2) General Director who performs the activities at the sectors of human resources, equipment and administration, Finance, Legal and Public Relations. Based on Mintzberg's principle of 5 basic configurations, the role of General Director which is the supporting staff is placed separately from the middle line. Therefore, an arrangement is necessary in order that the line function and the staff function are clearly depicted in the organizational structure.

\section{After Redesigning}

General Director who performs the auxiliary function turns into the Secretariat of the Company who is positioned at the right neck and reports to the Chief Director. Other reason that constitutes a background for this change is the study on the analysis of workloads which had been conducted by the company in 2012. Workloads among the members of the board of directors are not equal. Technical and Operational Director has a workload six times heavier than General Director. This heavy workload of Technical and Operational Director also constitutes a background for the addition of directors that perform the core business. Therefore, the line function (middle line) is managed by two Directors, Director of Service, who manages the handling of garbage and Director of Business, who manage the waste reduction.

The activity of waste handling is a routine activity performed by Technical and Operational Director, which includes the activities of sweeping, collection, transportation and disposal. Meanwhile, Director of Business performs a new working process relating to the waste reduction which comprises waste recycle and reuse. The background for naming Director of Business is that this sector has the responsible to turns waste into products which have a benefit value and a high sale value such as compost, biogas, etc. Therefore, Director of Business is the director that has the responsible to turn the cost center into the revenue center.

Through such a grouping process (see Fig. 2), it is expected that the organization structure may become the means of achieving the goals of the organization. 


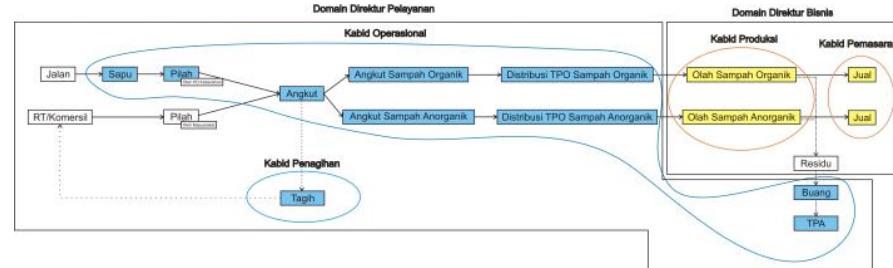

Fig. 2 Task Grouping of Middle Line at the Local Companion of Sanitation (PD Kebersihan) of Bandung City Grouping at the Office of Tax Service of Bandung City

Unlike the change in the organizational design at the Local Companion of Sanitation (PD Kebersihan) of Bandung City, regrouping of works at the Office of Tax Service of Bandung City is conducted partially, in which it is only focused on the Sectors of Registration Taxes and Stipulation Taxes (middle line level). Departmentalization of working units under both sectors initially was grouped based on the process, but during the implementation some problems arise, among other things, inequality of workloads among units. It constitutes a background for the change of the base for departmentalization, which initially a process-based becomes an output-based.

\section{Determining Tasks in Each Working Unit}

The next stage is to determine tasks in each working unit. The easiest method to determine the authority of each working unit is to identify main activities of the organization and then to determine the authority of each working unit by using the matrix of Responsible, Accountable, Consulted, and Informed (RACI). After all activities have been elaborated and the authority of each position to accomplish the activities has been mapped, at the next stage the job description of each position can be composed.

\section{Case Study}

The main focus in redesigning the Office of Tax Services of Bandung City lies at this stage. At this stage, the job description of some positions is specified to avoid an overlap of authority and to empower collection service unit (UPP).

\section{B. Which Department Alization Is The Best?}

This discussion will specifically look at which grouping pattern is the most effective if it is applied to the organization of local apparatus. Based on the research conducted on both organizations of local apparatus, the effective departmentalization uses the hybrid method. At the level of supporting staff, the most effective is the function-based method while at the middle line is the product-based method or the method which is based on the customers' areas:

(1) Middle line

a. Activity-based departmentalization at the middle line has some weaknesses, in which an overlap of works occurs, coordination is hard to achieve, and it makes a high level of relatedness of work performance among the units, in which a division has not yet been able to perform its work if other divisions have not yet finished their work. This work relationship is known by the term of sequential interdependence, in which the output of a work is needed to finish the next work (" $\mathrm{X}$ must act properly before $\mathrm{Y}$ can act"'[11]).

b. Product-based departmentalization facilitates the process of workload measurement so that managers can easily distribute the work.

(2) Supporting Staff

At the level of supporting staff more effective departmentalization is conducted based on management functions, such as human resource management, finance, etc. It refers to the types of supporting activities which generally are needed by all working units. The pattern of work relationship between supporting staff and other working units reflects a pooled task, in which other units are dependent on the same pool of resources.

\section{CONCLUSION}

There are five stages in performing the organizational design, namely to determine the direction of the change in the organizational design, to determine the workflow, departmentalization, and to determine tasks of each working unit. Based on the research conducted on both organizations of local apparatus, the effective departmentalization utilizes the hybrid method. At the level of supporting staff the most effective method is the function-based one while at the middle line is the product-based method or the method which is based on the customers' areas.

There is the limitation of this study, in which it is focused on the stages in designing the organization agreed in the internal environment of the Organization of Local Apparatus. However, the change in the organization of local apparatus is also determined by the approval of local legislative boards, in which through some consideration this design cannot be wholly adopted.

Further researches can focus on the effect of the change in the organizational design on the performance of both studied organizations of local apparatus. It is to find out to what extent the change has an impact on the improvement of the performance of the organization. Besides that, further researches can focus on some obstacles faced by managers in implementing the change. 


\section{REFERENCES}

[1] Rishipal, "Analytical Comparison of Flat and Vertical Organizational Structure", European Journal of Business and Management, Vol.6 No.36, pp 56-65, 2014

[2] McGee. E. Craig and Kathy Molloy, "Getting Results Through Organization Design”. Unpublish. 2003

[3] Ulrich. Dave, Jack Zenger, Norm Smallwood, "ResultBased Leadeship", Harvard Business School Press, Boston, 1999.

[4] Balogun. Julia, "The Practice of Organizational Restructuring: From Design to Reality", European Management Journal, Vol. 29, No. 1, pp 81-91, 2007

[5] Schilling, M.A. and Steensma, H.K., "The Use of Modular Organizational Forms: An Industry-level analysis. Academy of Management Journal 44, pp 11491168, 2001.

[6] Rugman, A. And Hodgetts, r. "The End of Global Strategy", European Management Journal 19 (4), pp. 332334, 2001

[7] Nonaka. Ikujiro dan Takeuchi Hirotaka, "The Knowledge Creating Company, How Japanese Create The Dynamic of Innovation", Oxford Univerity Press, NewYork, 1995

[8] Terry. G. R., "Principles of Management", Richard D. Irwin, Inc. Illinois: (1975:299)

[9] Mintzberg. Henry, "Structure in Fives". Prentice-Hall. Inc, New Jersey, 1993. pp. 1-23.

[10] Mansar, S.Limam and H.A. Reijers, "Best Practice in Business Process Redesign: Use and Impact", Business Process Management, Vol.13 No.2, pp 193-213, 2007

[11] Gittel. Jody Hoffer, "Relational Coordination Guidelines for Theory, Measurement and Analysis", www.bus.umich.edu, 2010. 